\title{
LA DIFÍCIL CONVIVENCIA ENTRE CRISTIANOS Y MUSULMANES EN UN TERRITORIO FRONTERIZO. LA GOBERNACIÓN DE ORIHUELA EN EL SIGLO XV
}

\author{
Juan Antonio Barrio Barrio*
}

\section{INTRODUCCIÓN}

Los estudios sobre los mudéjares hispánicos han experimentado un importante avance en las últimas décadas gracias a los artículos aparecidos en la revista Sharq al-Andalus y las ponencias y comunicaciones presentadas a los Simposia de Mudejarismo celebrados en Teruel. En esta línea de progreso también ha sido extraordinario lo que ha evolucionado el estado actual de nuestros conocimientos sobre los mudéjares valencianos gracias a los trabajos de Burns, Ferrer i Mallol e Hinojosa Montalvo, que han incidido especialmente en aspectos como la organización interna de la aljama, la demografía, la economía y la fiscalidad mudéjar. Las aportaciones de los dos últimos autores son fundamentales para entender aspectos vitales de las morerías mudéjares del sur del País Valenciano, encuadradas administrativamente en el territorio de la gobernación de Orihuela ${ }^{1}$.

Sin embargo, uno de los aspectos que ha tenido un tratamiento secundario en la historiografía sobre los mudéjares valencianos ha sido el intento de establecer morerías reales en localidades como Orihuela y Monforte durante el siglo $\mathrm{XV}^{2}$.

* Universidad de Alicante.

1. Una amplia bibliografía sobre estos autores y sobre el mudejarismo en general se puede encontrar en las páginas de la revista Sharq al-Andalus y en las ponencias y comunicaciones publicadas en los Simposia de Mudejarismo celebrados en Teruel.

2. Para Orihuela vid. A. Nieto FernándeZ, «La morería de Orihuela en el siglo XV», Primer Congreso de Historia del Pats Valenciano, II, Universidad de Alicante, 1980, pp. 761-771. Para Castellón vid. C. DIAZ DE RABAGO, La morería de Castelló de la Plana (1462-1527), Castellón, 1994. 
El presente artículo pretende abordar la difícil convivencia entre cristianos y musulmanes en la gobernación de Orihuela en el siglo $\mathrm{XV}$, a través de la problemática generada en torno al fracaso de la morería de Orihuela y al impulso dado por Juan II a la construcción de una morería real en la localidad de Monforte en 1459, a través de la concesión de una carta con las condiciones de poblamiento ${ }^{3}$. Monforte era en la segunda mitad del siglo XV una pequeña aldea dependiente de la villa de Alicante, situada en el valle de Elda y que contaba con una población mayoritaria de cristianos hasta la llegada de una serie de familias mudéjares de las morerías cercanas que intentaron colonizar estas tierras. Esta repoblación contrasta con el fracaso demográfico de la morería que erigieron las autoridades locales de Orihuela en la primera mitad del siglo XV.

Para entender la reacción que va a producir en comunidades cristianas como Orihuela y Alicante la creación de una morería en Monforte, conviene situar el proceso en el contexto histórico del territorio tras las traumáticas modificaciones que tendrá que soportar la población musulmana en su modus vivendi tras la conquista cristiana.

El desmoronamiento del poder árabe en al-Andalus y el impulso de la conquista cristiana en el siglo XIII, va a llevar la frontera de la cristiandad occidental hasta tierras valencianas y murcianas. Con la conquista cristiana, en la segunda mitad del siglo XIII, de las tierras al sur de Biar, la población musulmana se mantuvo concentrada sobre todo en zonas del interior, a pesar del incremento constante de la llegada de pobladores cristianos, sobre todo tras el fuerte impulso emprendido en la repoblación cristiana tras la represión de la revuelta mudéjar llevada a cabo por Jaime I. Ya desde finales del. siglo XIII y principios del XIV, periodo que coincide con la incorporación de las tierras meridionales del reino de Valencia, la población del valle del Vinolopó era mayoritariamente musulmana, mientras que la población cristiana se concentraba en el litoral ${ }^{4}$.

Estas morerías del interior albergaban una importante población musulmana que proporcionaba anualmente elevadas rentas tanto a la Corona como muy especialmente a los respectivos señores de las morerías situadas en el territorio. En las primeras décadas del siglo XIV los impuestos obtenidos de los mudéjares de Elche y Crevillente aportaron a la Corona la principal fuente de ingresos de las rentas reales obtenidas en la Procuración de Orihuela ${ }^{5}$. En el

3. Publicada por Enric GuINOT RODRíguez en Cartes de Poblament Medievals Valencianes, Valencia, 1991. Doc. n." 310 (1459, octubre, 15), pp. 674-678.

4. M. ${ }^{a}$ T. FERRER I MALLOL, «Els sarraïns del regne de Múrcia durant la conquesta de Jaume II (1296-1304)», Congreso Internacional Jaime II 700 años después. Actas, Anales de la Universidad de Alicante, 11 (1997), pp. 173-200.

5. J.A. BARRIO BARRIO, «Las rentas reales en la procuración de Orihuela, 1305-1324», Congreso Internacional yaime II 700 años después. Actas, Anales de la Universidad de Alicante, 11 (1997), pp. $43-64$. 
siglo XIV y XV las principales morerías del territorio son las de Elche, Crevillente y las situadas en el Valle de Elda, todas ellas bajo dependencia señorial, salvo breves periodos, como el comprendido entre 1305 y 1324 en que Elche y Crevillente se incorporaron al patrimonio real. Las morerías más pobladas de la gobernación están en el interior y bajo dominación señorial ${ }^{6}$.

En la segunda mitad del siglo XV en el valle de Elda, poblado mayoritariamente por mudéjares, encontramos las villas y castillos de Elda, Aspe, Novelda, Petrer y el lugar de Salinas que generaban una amplia gama de rentas sobre la producción agraria, las actividades industriales y sobre el comercio ${ }^{7}$.

\section{LA POSICIÓN DE LOS CRISTIANOS ANTE LAS MORERÍAS DE LA GOBERNACIÓN}

La actitud y la posición mostradas por las autoridades de Orihuela, la localidad de realengo más importante de la gobernación y con población mayoritaria cristiana, fueron ambivalentes frente a la población mudéjar. Por una parte intentando atraer a musulmanes para poblar la localidad y construir una morería, facilitando el asentamiento de los nuevos pobladores, y por otra manifestando su rechazo hacia los miembros de esta misma comunidad religiosa que vivían en morerías cuya población era en su mayoría musulmana, como las cercanas localidades de Novelda, Aspe, Elda, etc. Hay un deseo de convivir con un grupo de musulmanes que se encuentran en una situación de minoría en Orihuela al mismo tiempo que se van a manifestar una serie de tensiones con los musulmanes que en situación de mayoría viven en las citadas morerías.

Los temores que manifiestan estos cristianos que gobiernan en un municipio como Orihuela demuestran que para ellos ni la conquista llevada a cabo por sus antepasados ni la represión de las revueltas capitaneadas por mudéjares han terminado con el peligro de la frontera interna, que hay que reconquistar empleando las armas si es preciso.

Para los oriolanos el moro puede ser peligroso. En unos capítulos redactados en 1433 para solucionar el problema del Vicariato, las autoridades

6. En la ponencia que presentó Dolors Bramón sobre los mudéjares valencianos en el IV Simposio Internacional de Mudejarismo celebrado en Teruel en 1987 dejó totalmente claro que los mudéjares en sus migraciones prefieren asentarse en territorio señorial: «Estado de cuestión de los estudios económicos sobre los mudéjares valencianos», Teruel, 1992, p. 234.

7. J.A. Barrio Barrio y J.V. Cabezuelo Pliego, «Rentas y derechos señoriales de las morerías del valle de Elda a finales del siglo XV», VII Simposio Internacional de Mudejarismo, Teruel, 19-21 septiembre de 1996 (en prensa). 
locales exponían el caso de un asesino musulmán que se había convertido engañosamente al cristianismo y lo definían como "tan malvada persona e moro dispost a tot mal a fer" ${ }^{\prime \prime}$. En el mismo documento los oriolanos se sienten vejados por el obispo de Cartagena, ya que como súbditos del rey de Aragón son tratados con clara discriminación respecto a los castellanos, ya que a un castellano, incluso si es musulmán o judío, se le cobra un morabetino que vale cuatro dineros pero si es catalán se le cobra un sueldo que vale tres veces más (12 dineros) $)^{9}$. El hecho de que se les discrimine frente a judíos o musulmanes hace todavía más grave la ofensa y ante la posibilidad de que la villa sea tomada por granadinos se cita textualmente "per enemichs del senyor Rey e de la Santa Fe Catholica"10. Haciendo igualmente referencia al peligro de los moros granadinos que esperan en los caminos despoblados a los cristianos para apresarlos y llevarlos al corral de Granada ${ }^{11}$.

\section{TEMORES Y TENSIONES CON LAS MORERÍAS DEL TERRITORIO}

Los miedos de los gobernantes cristianos de Orihuela ante el Islam peninsular en la primera mitad del siglo XV, como veremos en las líneas siguientes, se pueden resumir en tres: morerías muy pobladas, cercanas e insuficientemente controladas militar y jurisdiccionalmente; los delitos impunes de plagi y collera perpetrados por musulmanes; y la libertad de acción y movimiento de los almogávares granadinos.

Los gobernantes de Orihuela en el siglo XV advertían un claro peligro en las morerías cercanas. En 1417, alboreando el reinado de Alfonso V, las autoridades locales de Orihuela tenían una percepción clara y nítida de la realidad fronteriza. Situaban su territorio rodeado de dos fronteras exteriores: el reino de Castilla y el granadino, y en retaguardia una frontera interior ${ }^{12}$, haciendo referencia a las comunidades mudéjares que circunvalaban el territorio oriolano a las que consideraban como enemigas de la cristiandad. En el valle de Elda cifraban en más de tres mil el número de potenciales enemigos, que estaban ubicados a cinco leguas. A tres o cuatro leguas tenían las morerías de Elche, Crevillente, Asprella ${ }^{13}$, Albatera, Abanilla, Fortuna y el valle de

8. A(rchivo) M(unicipal) de O(rihuela), Contestador, n." 21, f. 115r (1433, diciembre, 15).

9. AMO, Contestador, n." 21, f. 112 r-v (1433, diciembre, 15).

10. AMO, Contestador, n.' 21, f. $116 \mathrm{v}$ (1433, diciembre, 15).

11. AMO, Contestador, n." 21, f. $125 \mathrm{v}$ (1433, diciembre, 15).

12. J.E. LOPEZ DE COCA CASIANNER, «Los mudéjares valencianos y el reino nazarí de Granada. Propuestas para una investigación», En la España Mediezal. Homenaje a Salvador de Moxó, Madrid, 1982, I, pp. 643-666.

13. Alquería de Elche habitada por mudéjares con aljama independiente de la de Elche en el siglo XIV. M.T. FERRER I MALLOL, Les aljames sarrä̈nes de la Governació d'Oriola en el segle XIV, Barcelona, 1988, pp. 64-65. 
Ricote, en las que calculaban en más de cinco mil el número de mudéjares ${ }^{14}$. Por una parte las morerías más pobladas situadas en la frontera interna de la gobernación, como la de Elche y las del valle de Elda, y por otra, las morerías más pobladas de la frontera exterior situadas en el reino de Murcia, como las del valle de Ricote y las de Abanilla y Fortuna, que eran los dos núcleos mudéjares más próximos a la frontera cuando el reino de Murcia quedó dividido tras el tratado de Torrellas-Elche de 1304-1305 $5^{15}$.

Algunos de los incidentes más espectaculares entre Orihuela y las comunidades mudéjares de la gobernación se produjeron en la década de 1420, como muestra del recelo entre cristianos y musulmanes.

En marzo de 1420 unos moros de Crevillente y Novelda atacaron la huerta de Orihuela matando a algunas personas y cautivando a otras. Para castigar la acción, el gobernador y su lugarteniente se aprestaron a detener a los sospechosos que se encontraban en el lugar de Novelda, negándose el señor del lugar, Pere Maça, a entregar a los musulmanes acusados ya que poseía el mero y mixto imperio sobre el lugar.

Esta negativa obligó al gobernador a organizar una hueste para apresar a los culpables, que se encontró con la resistencia armada de Pere Maça, que había reunido unas tropas, con peones y caballeros, para impedir la acción militar del gobernador, evitando que el oficial real detuviese a los acusados de la acción en la huerta de Orihuela. Ante estos hechos tan graves se produjo la intervención real, a través de sendas recriminaciones que cursó Alfonso $\mathrm{V}$ al gobernador y a Pere Maça. El rey pedía al gobernador que ejerciera su jurisdicción con justicia y por vía civil, sin emplear la fuerza de las armas, para evitar escandalos e inconvenientes y le informaba que había ordenado a Pere Maça la detención de los culpables y su encierro en prisión ${ }^{16}$. Al mismo tiempo Alfonso V se dirigía a Pere Maça para mostrarle su profunda indignación por su actuación, al reunir tropas para resistir al gobernador ${ }^{17}$. Las palabras del rey son elocuentes: "son maravellats mas encara indignats contra nos per les dites coses per nos axi atentades en menispreu de nostra Reyal maiestat e correccio digne de gran e a gra punicio"18.

14. J.A. BARRIO BARRIO, «La frontera marítima en Orihuela durante el reinado de Alfonso $\mathrm{V}$ (1416-1458)», La Frontera Oriental Nazari como sujeto histórico (s. XIII-XVI), Lorca-Vera, 22/24 noviembre 1994.

15. M. at. FERRER i MALlol, «Els sarraïns del regne de Múrcia durant la conquesta de Jaume II...». Sobre los mudéjares murcianos vid. A.L. Molina Molina y M. ${ }^{a}$ C. VEas Arteseros, «Situación de los mudéjares en el reino de Murcia (siglos XIII-XV)», La sociedad murciana en el tránsito de la Edad Media a la Modema, Murcia, 1996, pp.65-83.

16. A(rchivo) del R(eino) de V(alencia), Real, reg. 232, f. $31 \mathrm{v}(1420$, marzo, 14).

17. ARV, Real, reg. 232, f. 32r (1420, marzo, 14).

18. Ibidem. 
La intervención de Alfonso V ponía las causas en su sitio, ya que ordenaba al gobernador juzgar a los mudéjares en Novelda, sin vulnerar de esta forma los derechos jurisdiccionales del señor del lugar.

El ataque realizado por musulmanes de Crevillente y Novelda en 1420 a la huerta de Orihuela evidenciaba el peligro que suponía la comunidad mudéjar de Crevillente para los cristianos que habitaban en Orihuela y su huerta. Para intentar garantizar su seguridad Alfonso V ordenó al gobernador en 1424 que junto a los jurados de Orihuela tomase las medidas oportunas, militares y judiciales, para proteger a los cristianos de Orihuela y de los lugares de Catral y Almoradi ${ }^{19}$.

En 1421 se desarrollaba un conflicto jurisdiccional entre las autoridades locales oriolanas y el procurador de Elche. El motivo de discordia era un "moro plagiario" detenido en Elche ${ }^{20}$. Las autoridades de Orihuela reclamaban la jurisdicción sobre el detenido para el gobernador del territorio, mientras que el procurador de Elche se la arrogaba por unos privilegios concedidos por la reina. En reclamación elevada a la soberana, los munícipes oriolanos se lamentaban de esta situación y afirmaban con rotundidad que esta medida iba contra los fueros del reino y les perjudicaba gravemente, ya que Crevillente estaba poblada exclusivamente por mudéjares y Elche en su mayoría también y la gobernación se encontraba en frontera del reino de Granada y los habitantes de estas dos localidades habían cometido habitualmente el crimen de plagio con correligionarios del reino de Granada. Afirmaban además que dichos actos se habían realizado cuando el gobernador de Orihuela había sido privado de la jurisdicción sobre los delitos de plagio y collera en estas localidades señoriales, en beneficio de su procurador que no la ejecutaba por las amenazas de los mudéjares de despoblar la localidad.

En este contexto y según lo expuesto por las autoridades de Orihuela los musulmanes cautivaban y mataban a cristianos: "esser fets e perpetrats per los dits moros molts cativeris e morts de vostres vasalls cristrans" 21 .

Cuando se producía un ataque sobre cristianos y se seguía el rastro a los atacantes, la pista llevaba a las morerías de Elche y Crevillente y como el gobernador no podía entrar en estas plazas para liberar a los cristianos cauti-

19. ARV, Real, reg. 32, f. 93r (1424, julio, 4).

20. El conocimiento del crimen de plagi o collera correspondía en exclusiva a la justicia regia y hacía referencia al rapto de personas con el objetivo de obtener un beneficio económico ilegal por su rescate o su venta como esclavos. J.V. CABeZLelo Pliego, Poder Público y Administración Territorial en el reino de Valencia, 1239-1348. El Oficio de la Procuración, Universidad de Alicante, 1996, Tesis doctoral inédita, tomo II, f. 855. Gentileza del autor.

21. AMO, n." 19 , f. $50 \mathrm{v}$. 
vos y apresar a los malhechores, esta situación tenía atemorizados a los habitantes cristianos del término de Orihuela.

En esta misma carta las autoridades locales oriolanas aseveraban que si el gobernador recibía la jurisdicción sobre estos crímenes, los mudéjares abandonarían estas actividades y el territorio estaría en paz ${ }^{22}$.

Otro momento de inestabilidad se produjo en noviembre de 1427 . En una reunión del consell de Orihuela celebrada el diecinueve de noviembre ${ }^{23}$, el gobernador Pere Maça informó que estando en Novelda fue advertido sobre un "moro plagiario" que se encontraba en Elda y había pasado otros musulmanes de la corona de Aragón al reino de Granada y apresado cristianos que llevaba al reino de Granada. Por lo que acudió inmediatamente al lugar de Elda con el noble Pere Rocafull, donde toparon con la resistencia que les presentó el alcaide del castillo y procurador de la villa, que se negó a entregar al mudéjar plagiario, alegando que en la tierra de mosén Corella, señor del lugar, no reconocía a ningún oficial del rey. Además el alcaide había alborotado a los musulmanes que estaban armados con lanzas y ballestas, dispuestos a matar a Pere Maça y a su compañía. Por lo que el gobernador tuvo que abandonar el lugar huyendo precipitadamente.

El consell de Orihuela, tras ser informado de todos estos hechos personalmente por el gobernador, le aconsejó convocar la hueste de la gobernación con tropas de peones y caballeros para reprimir la revuelta de los mudéjares de Elda y para restituir la ofensa causada al rey: "per forma que sia reintegrada la injuria que es stada feta a la persona del dit molt alt senyor Rey" 24 .

En la siguiente reunión que celebró el consell oriolano el 27 de noviembre, el propio gobernador informó que la hueste que acudió al valle de Elda para acabar con la resistencia de los mudéjares del lugar tuvo que actuar con contemplación por la llegada de dos mensajeros de Valencia, que en nombre del rey pedían a Pere Maça que no tomase la villa por la fuerza de las armas. Por ello fue ocupada en nombre del rey, con la instalación de las enseñas reales. Además el gobernador nombró un nuevo alcaide en el castillo, y oficiales en el consell en nombre del rey. Aunque el documento no aclara las medidas expeditivas tomadas por la expedición, es probable que la llegada de los mensajeros valentinos evitara un baño de sangre ${ }^{25}$.

Sobre la importancia de las morerías del valle de Elda tenemos un dato de 1460 que sirve para calibrar tanto la demografía mudéjar en el territorio como el potencial valor económico de sus aljamas. El 5 de abril de 1460 Juan

22. $\mathrm{AMO}, \mathrm{n} .{ }^{\circ} 19, \mathrm{ff} .50 \mathrm{v}-51 \mathrm{r}$ (1421, febrero, 23).

23. AMO, n. ${ }^{\circ} 20$, ff. $148 \mathrm{v}-150$ (1427, noviembre, 19).

24. AMO, n." 20, f. 150r.

25. AMO, n.' 20, ff. 150r-151v (1421, noviembre, 27). 
II enviaba una carta a Jaume Roca, baile general del reino de Valencia dellà Xixona, para informarle de las quejas que había recibido de los mensajeros de Alicante y Orihuela por las grandes morerías pobladas del valle de Elda, que alcanzaban una cifra de entre setecientas y mil casas, lo que podía suponer un peligro ya que se encontraban en frontera con Castilla y en los confines del reino de Granada. Para los cristianos el paso por dichos lugares era muy peligroso por la posibilidad de entrada de almogávares en el territorio, dadas las facilidades que éstos tenían por el apoyo prestado en territorio de la gobernación oriolana por sus correligionarios de las morerías ${ }^{26}$.

Así, cuando se inicia el poblamiento de la localidad de Monforte por mudéjares la reacción de las autoridades locales de Orihuela será virulenta. En un escrito remitido al rey le informan que la llegada de mudéjares a Monforte está alejando del lugar a los pobladores cristianos y está privando a este islote cristiano, en territorio de "moros", de defensores ante la llegada de almogávares granadinos que actúan impunemente en el territorio.

Evidentemente, para las autoridades cristianas de Orihuela los musulmanes que vivían en Elche, Crevillente y el valle de Elda eran enemigos potenciales por su complicidad con los almogávares granadinos, pero si alguno de estos mismos musulmanes acudía a poblar Orihuela era recibido con los brazos abiertos. La benevolencia con los mudéjares se produce cuando son necesarios retomando la frase clásica de $\mathrm{Gual}^{27}$ y pueden ser controlados. Este utilitarismo de los mudéjares impulsó la construcción de la morería de Orihuela y la política de atracción de pobladores musulmanes a la localidad.

\section{ATRACCIÓN DE MUdÉJARES. INTENTOS DE CREACIÓN DE MORERÍAS PROPIAS. LA MORERÍA DE ORIHUELA EN EL SIGLO XV}

Frente a esta actitud de confrontación con las morerías de la gobernación, la ciudad de Orihuela realizó durante la primera mitad del siglo XV un esfuerzo denodado para atraer a pobladores musulmanes a su localidad y poder establecer una morería próspera.

Ante el rechazo a miembros de comunidades que practican otra religión y son potencialmente peligrosos como quinta columna, también es posible encontrar motivaciones económicas en estos recelos. El caso de Monforte demuestra cómo los cristianos que poblaban esta localidad son desalojados pacíficamente por la llegada de familias musulmanas laboriosas que com-

26. ARV, Real, 92, ff. 105r-(bis)-106v-(bis) (1460, abril, 5).

27. M. Gual CAMARENA, «Los mudéjares valencianos en la época del Magnánimo», IV Congreso de Historia de la Corona de Aragón, Palma de Mallorca, 1959, t. I, p. 469. Utilizada por Dolors Bramón en su obra Contra moros y judios, Barcelona, 1986, p. 78. 
pran casas y tierras y progresan económicamente arrinconando a algunas familias cristianas que abandonan la localidad.

En Orihuela ya conocían esta problemática, al menos desde principios del siglo XV, por las ordenanzas que aprobó su consell en 1417 y 1451, prohibiendo a los vecinos de Elche y Crevillente, localidades con población musulmana, coger junco, carrizo y realizar sosa en el término de Orihuela ${ }^{28}$.

Orihuela había perdido la mayor parte de su población mudéjar tras la guerra de los dos Pedros. Durante la primera mitad del siglo XV el consell de Orihuela, ante la necesidad de mano de obra para las tareas agrícolas de la huerta ${ }^{29}$, intentó atraer pobladores mudéjares y establecer una morería en la localidad. Los únicos datos demográficos fiables que conocemos para estudiar la inmigración en este período proceden de un cuaderno -llibre de avehinaments- que recoge los avecindamientos registrados en Orihuela entre 1421 y $1428^{30}$ y presenta un total de 128 pobladores y sus respectivas familias. La mayoría de los inmigrantes son cristianos. Sólo hay ocho familias de judíos y tres de musulmanes que procedían de Elda y Elche. El poco atractivo que presentaba Orihuela para los pobladores musulmanes en este periodo coincide además con una década en la que hubo episodios críticos entre la villa de Orihuela y las comunidades de Elche y Elda.

Para la construcción de la morería de Orihuela y su repoblación, hay una primera licencia concedida en octubre de 1431 por Alfonso $V$ a las autoridades reales y locales de Orihuela para fijar las condiciones de poblamiento de la morería. Asimismo el monarca autorizaba a los musulmanes del reino a acudir a poblar dicha morería sin necesidad de pedir licencia al baile ${ }^{31}$. El Magnánimo había prohibido en noviembre de 1418 a los mudéjares del reino pasar de la línea de Biar hacía el sur bajo pena de cautiverio, ante la posibilidad de huida al reino de Granada. A petición del consell de Orihuela, Alfonso $\mathrm{V}$ concedió este permiso a los mudéjares del reino, con la salvedad que tenían que dirigirse desde el punto de destino directamente a Orihuela y presentarse al justicia criminal y los jurados de la localidad nada más llegar, debiendo realizar el avecindamiento con el juramento pertinente de habitar y residir en la villa ${ }^{32}$. Para obtener esta facultad los argumentos expuestos por las autoridades oriolanas eran la despoblación de la villa y es-

28. AMO, Contestador, n. ${ }^{\circ} 16$, f. 136 r (1417, agosto, 21); n. ${ }^{0} 29$, f. $35 \mathrm{v}$ (1451, febrero, 6).

29. A. NIETO FERNANDEZ, «La morería de Orihuela en el siglo XV...», p. 762.

30. Un estudio sobre la inmigración en Orihuela a partir de los datos recogidos en dicho cuaderno fue presentado a las II Jornadas de Estudios sobre la Población Valenciana, celebradas en Orihuela los días 23, 24 y 25 de septiembre de 1996 con el título «La inmigración en Orihuela entre 1421 y 1428 ».

31. E. Guinot Rodríguez, Cartes de Poblament Medievals..., doc. n." 309 (1431, octubre, 10), pp. 672-674.

32. ARV, Real, 50 , ff. $16 \mathrm{v}-17 \mathrm{r}(1431$, agosto, 1$)$. 
pecialmente la escasez de labradores para cultivar la feraz huerta que era una de las partes más importantes del término y causa de la repoblación y el crecimiento de la localidad. En la defensa de su solicitud informaron al monarca que algunos mudéjares del reino habían manifestado su deseo de poblar Orihuela si se revocaba la provisión que les limitaba su circulación por el sur del reino: "alguns moros del dit Regne han en voluntat de star e fer lur domicili en la dita vila en correar laurar e cultivar la dita orta"33.

En 1446 tras el acuerdo correspondiente del consell oriolano, el municipio adquirió unos solares para edificar diez casas y una mezquita y facilitar de esta forma el establecimiento de los mudéjares en la localidad. De los gastos municipales en obras públicas en $1446 \mathrm{el} 77 \%$ se destinó a la obra de la morería, con una inversión superior a los 5.000 sueldos $^{34}$. En 1446 se realizó un pregón público de los capítulos de la morería aprobados en 1431 dirigido a las aljamas del reino de Valencia y de Castilla ${ }^{35}$. Los primeros pobladores se establecieron en 1447 y la obra definitiva de la morería tuvo que terminar entre 1448 y $1449^{36}$. Precisamente en 1449 ante las pocas familias musulmanas llegadas a Orihuela y el cierre de algunas casas de la morería por sus pobladores musulmanes, que se habían ido a Elche $^{37}$ conservando la propiedad, el consell aprobó diversas ordenanzas para incentivar la llegada de nuevos pobladores de localidades como el valle de Elda, que serían aceptados inmediatamente como nuevos vecinos. Las autoridades locales entregarían estas casas a los nuevos ocupantes musulmanes, estableciendo que debían habitar en la morería con su familia de forma continua, si querían conservar sus casas.

Por otra parte, los mudéjares solicitaron al consell que no permitiera que en la morería habitara entre ellos ningún cristiano, ni por alquiler ni por compra, ni que construyeran casas en la morería. El consell ordenó que ningún cristiano pudiera estar en la morería. El consell también determinó que en cumplimiento de los capítulos de la morería los mudéjares pudieran elegir alcadí y aljama.

A pesar de todas estas ventajas concedidas a los nuevos pobladores mudéjares, la morería oriolana quedaba despoblada en 1451 y en ese mismo año el municipio aprobaba la edificación de un monasterio en el solar de la morería, cediendo la propiedad del mismo a los franciscanos ${ }^{38}$.

33. ARV, Real, 50, f. 16v (1431, agosto, 1).

34. J.A. BARRIO BARRIO, El ejercicio del poder en un municipio medieval: Orihuela 1308-1479, Alicante, 1993 (tesis microfichada).

35. AMO, Contestador, n. 27, f. 114 (1446, noviembre, 11).

36. A. NIETO FERNANDEZ, «La morería de Orihuela en el siglo XV...», p. 767.

37. Ibídem, p. 770

38. Ibidem, pp. 770-771. 
Un año antes el consell de Orihuela, a pesar del gasto realizado en inversiones públicas, tuvo la "delicadeza" de aprobar una ordenanza vejatoria y represiva hacia los mudéjares y judíos de Orihuela y que afectaba también a sus correligionarios transeúntes. La medida obligaba en Orihuela y en todo su término, a todos los judíos y musulmanes, vecinos o no, a arrodillarse y orar siempre que escuchasen la señal de que en las iglesias se elevaba el cuerpo de Cristo, conforme a una práctica que recientemente se había introducido en Orihuela, cuando escuchasen la señal de la oración que se acostumbraba decir cada noche, al ponerse el sol, cuando vieran la cruz y el paso del viático por la ciudad o las aldeas del término ${ }^{39}$. Una medida similar estaba en vigor en el reino de Valencia desde 1314, por la que los judíos tenían. que arrodillarse en muestra de reverencia si coincidían con el paso público del Santísimo Sacramento ${ }^{40}$.

El edicto, que fue pregonado públicamente, era un desprecio a los miembros de ambas comunidades religiosas ya que literalmente expresaba que "nos volen agenollar ne fer oraçio a llur creador". Además esta actitud para los cristianos era despreciable, ya que "en gran menys preu de deu e vergonya de xristians voler comportar tan gran inobediencia com per los dits moros e juheus es comesa vers nostre senyor deu". Por ello obligaban a judíos y musulmanes a humillarse públicamente a diario: "los dits juheus e moros devotament se sien tenguts agenollar e fer aquella reverençia e honor ques pertany com a lur senyor e credor".

La multa fijada por vulnerar esta ordenanza era de 5 sueldos por cada infracción. El importe se destinaría en dos terceras partes para obras de reparación de dos iglesias de la localidad, siendo la cantidad restante para el acusador. El impago de la multa equivalía a cinco días de arresto en la cárcel de la ciudad. Sobre esta multa no se podía hacer gracia o remisión como en otros delitos $^{41}$. La medida afectaba de la misma manera a los judíos y musulmanes cautivos en Orihuela y su término.

\section{LA CREACIÓN DE LA MORERÍA DE MONFORTE}

Durante el siglo XIV Nompot, nombre antiguo de Monforte, fue una aldea dependiente de Alicante con la que mantuvo rivalidades y pleitos para

39. AMO, Contestador, n." 29, f. 8r (1450, diciembre, 27).

40. D. Bramón, Contra moros y judíos, Barcelona, 1986, pp. 51-52.

41. El Justicia criminal de Orihuela tenía la prerrogativa de absolver las multas, igual que el justicia de Valencia, quien desde tiempos de Jaime I podía perdonar cualquier tipo de sanción civil y criminal, excepto aquellos delitos graves penados con mutilación o muerte. J.A. Barrio BARRIO, Gobierno municipal en Orihuela durante el reinado de Alfonso V, 1416-1458, Alicante, 1995. 
poder obtener su independencia ${ }^{42}$. Desde principios del siglo XIV estaba poblada por propietarios libres en su mayoría cristianos, aunque también hubo una población musulmana minoritaria ${ }^{43}$.

La principal actividad económica de los mudéjares que se instalaron en Monforte en la segunda mitad del siglo XV era la agricultura, como en sus zonas respectivas de origen donde conservaban tierras que labraban. En las tierras de origen los cultivos eran el trigo, cereales menores como panizo, centeno y la cebada, además de la pasa y los higos. Una producción similar es la que debieron cultivar los mudéjares que se instalaron en Monforte.

En el siglo XIV la corona había refrendando un acuerdo entre Alicante y Monforte, que eximía a la aldea de ciertas contribuciones comunales, para aliviar a sus habitantes del gasto realizado en los servicios de vigilancia del territorio prestados a la corona, ante la entrada de almogávares grana$\operatorname{dinos}^{44}$. Dado el poblamiento cristiano de la aldea y por su ubicación estratégica, por la cercanía de las comunidades mudéjares del valle de Elda, sospechamos que desde la conquista cristiana a la aldea y a sus habitantes se les confió esta misión de vigilancia y persecución de los almogávares.

Juan II aprobó en 1459, a instancias de los musulmanes de Monforte, capítulos para establecer una morería real ${ }^{45}$. En la exposición del texto aprobado se recoge lo beneficioso que había sido la llegada de mudéjares a Monforte para la reactivación económica de la localidad e incluso para los propios cristianos.

\section{LOS CAPÍTULOS APROBADOS POR JUAN II}

El 15 de octubre de 1459 Juan II aprobó unos capítulos que le habían sido presentados por Taher Alazarach como síndico de la aljama de la morería de Monforte. En primer lugar exponía los motivos de su solicitud y las ventajas del establecimiento de una morería real en Monforte.

- Recientemente se había edificado una "bella" morería en el lugar de Monforte. La aljama planteaba al rey que podía producir un aumento de las regalías y derechos de la corona, con la construcción de más de veinticinco

42. Para el intento de segregración de Monforte en el siglo XIV vid. J.V. CabezueLo Plieco, «Un caso fallido de segregación en el Medio Vinalopó a mediados del siglo XIV. La aldea de Nompot», Anales de la Universidad de Alicante. Historia Medieval, n." 9, Homenaje al Dr. D. Juan Manuel del Estal Gutiérrez, Alicante, 1995, pp. 241-255.

43. M. ${ }^{\mathrm{a} T}$. Ferrer I Mallol, Les aljames sarraïnes de la Governació d'Oriola en el segle XIV, Barcelona, 1988, pp. 14-15.

44. J.V. CABezUelo Pliego, «Un caso fallido de segregación...»», pp. 246-247.

45. ARV, Real, 283, ff. 136v-139v (1459, octubre, 15). E. Guinot Rodríguez, Cartes de Poblament Medievals..., doc. n." 310 (1459, octubre, 15), pp. 674-678. 
casas y mezquita. Asimismo se compraban casas y solares para edificar nuevas viviendas para atraer a nuevos pobladores. También se compraban heredades y otros bienes para habitar permanentemente en dicho lugar.

Por ello se producía una llegada constante de nuevos pobladores que establecían sus casas en la localidad. La morería estaba siendo repoblada por mudéjares procedentes del Xarch, Crevillente, Aspe, Elda y Novelda. Todos estos pobladores se convertían en súbditos del rey al instalarse en la morería de Monforte. Además la llegada de nuevos pobladores era beneficiosa para la regalías de la Corona y para el lugar, ya que estaba aumentado el valor del precio de la tierra, que había subido de veinte florines a cincuenta florines. En la propuesta presentada por el síndico se resaltaba que los nuevos pobladores musulmanes iban a contribuir en las obras del castillo y en otras cargas vecinales, como sisas y otras imposiciones municipales. Con estas contribuciones podían ayudar a los cristianos del lugar.

Para poder acudir a poblar Monforte los mudéjares de Novelda habían tenido problemas en su lugar de origen con las autoridades de la localidad, que les impedían recoger y llevarse los frutos y productos de sus cosechas. Además se les había amenazado y presionado para que retornasen a Novelda, además de recibir "e moltes altres vexacions les quals serien largues explicar" ${ }^{46}$. Alegaban los nuevos pobladores monfortinos que lo normal era que los señores permitiesen a sus vasallos abandonar libremente sus casas para instalarse en otra localidad, y poder recoger y llevarse sus frutos y cosechas pagando los impuestos correspondientes. Esta situación se producía en diferentes localidades donde mudéjares de un lugar poseían casas y tierras en otras localidades:

- Mudéjares de Albatera poseen heredades en Aspe.

- Mudéjares de Aspe tienen casas y heredades en Elche.

- Mudéjares de Novelda tienen casas y heredades en Aspe.

- Mudéjares de Orihuela tienen heredades y casas en Elche.

Estos musulmanes, que contribuyen con las cargas correspondientes al señor del lugar donde tienen heredades y casas, no tienen ningún problema para sacar las cosechas producidas en estos lugares. Lo expuesto anteriormente demuestra que frente a las fronteras jurisdiccionales que fijaban las leyes sobre cada territorio y las barreras mentales que establecen los hombres en cada comunidad, la población musulmana de la gobernación se muestra en esta centuria interesada en la movilidad espacial para el mejor aprovechamiento de los recursos del territorio.

46. ARV, Real, 283, f. 137r. 
Por todo ello los mudéjares de Monforte solicitaban a Juan II la aprobación de los siguientes capítulos:

1. Que el baile general dellà Xixona nombre en dicha morería un alcadí que tenga jurisdicción sobre los "moros" de dicho lugar según Xuna e Sara y según costumbre practicada en otras morerías del reino de Valencia. El rey acepta la petición.

2. Que los "moros" de dicha morería puedan elegir dos jurados y vells aljama y un çahat medina para ejecutar las órdenes de aquellos, y un alamí que es denominado mustaçaf. La elección se debe celebrar cada año en el mes y día correspondiente, según la forma acostumbrada. Los cargos de jurados, çahat medina y alamí serán designados por el alcadí y vells de la aljama. Correspondiendo al baile general o su lugarteniente la confirmación. $\mathrm{Si}$ el baile o su lugarteniente no considera idóneos a los elegidos, podrá designar a otros en su lugar. El rey acepta todo lo anterior y dispone que el resultado de las elecciones debe presentarse cada año al baile general o a su lugarteniente el último día del año.

3. Como algunos de los mudéjares que acuden a Monforte son maltratados por las autoridades del lugar de origen, como es el caso mencionado de Novelda, solicitan al rey protección contra este tipo de abusos y poder acudir a poblar Monforte sin sufrir vejaciones y no perder el derecho de uso sobre las tierras y casas que tuvieran en sus lugares de origen y poder acudir sin temores a estas localidades a cultivar sus tierras. Piden poder disfrutar en igualdad de condiciones del trato que por ejemplo reciben los vasallos de señores que tienen propiedades en localidades de realengo y no son perturbados en el uso y disfrute de estos bienes. Por ello solicitan poder sacar de estos lugares los productos que cultivaban como trigo, panizo, centeno, cebada, pasa y los higos. El rey acepta esta exigencia. La principal obligación de los mudéjares que acudían a poblar Monforte era prestar juramento ante los jurados de Alicante y ante el baile general de "fer vassallatge en lo dit loch" y tener aquí su domicilio y casa principal al menos durante los próximos cinco años y habitar en dicho lugar con sus mujeres, hijos y familia. Por incumplir esta obligación serían castigados con una multa de mil sueldos ${ }^{47}$, sin poderse realizar remisión alguna sobre dicha pena. Además se fija la obligación para todo poblador musulmán que durante los dos primeros años debe construir por su cuenta una casa "ben fortificat e abte para poder star e habitar en aquell" con la supervisión del baile general o su lugarteniente o pagar a dicho baile el importe de obrarla. Para el cumplimiento del presente capítulo los nuevos pobladores debían presentar al baile las garantías y fianzas suficientes.

47. Dividida la multa en tercias. Una para el rey, otra para la obra del castillo de Monforte y la tercera para la obra del castillo de Alicante. 
4. Para la tranquilidad de los habitantes del lugar se solicitaba al rey prohibir a cualquier oficial, excepto al baile general y su lugarteniente, entrar en la morería para juzgar o realizar cualquier acto. Esta potestad sólo podía ser ejercida por el baile general o su lugarteniente, como juez ordinario en las causas entre mudéjares. Se afirmaba en la solicitud que otros oficiales reales, refiriéndose con toda seguridad al gobernador, bajo la excusa de administrar justicia, realizaban vejaciones a los mudéjares, perjudicando el oficio de la bailía general y a los propios musulmanes. El rey acepta que se practique como en otras morerías del reino de Valencia.

Estos capítulos permitían a los mudéjares de las morerías cercanas instalarse en el lugar de Monforte en condiciones ventajosas bajo la dependencia de la Corona en la reciente creada morería real. Situación que va a provocar la reacción adversa de las comunidades cristianas de Orihuela y Alicante.

\section{PROBLEMAS CAUSADOS A LOS CRISTIANOS POR LA MORERÍA DE MONFORTE}

Ante la concesión de los capítulos de la morería de Monforte en octubre de 1459, la reacción de las comunidades cristianas de Orihuela y Alicante fue inmediata. En abril de 1460 el rey escribía a Jaume Roca, baile general del reino de Valencia dellà Xixona, ante las quejas presentadas por los mensajeros de Orihuela y Alicante:

- Informan al rey que las morerías del valle de Elda están muy pobladas, entre setecientas y mil casas. Situadas en frontera de Castilla y cerca del reino de Granada.

- Cuando musulmanes almogávares del reino de Granada entran en el reino pasan cerca de Monforte. Si este lugar es destruido los almogávares granadinos y los renegados cristianos podrán saltear, matar y atacar a los cristianos que pasan cerca de dicho lugar, ya que la localidad poblada de cristianos más cercana a Monforte es Elche, que está a más de tres leguas de distancia de dicho lugar ${ }^{48}$. En el lugar de Monforte el número de casas se sitúa entre sesenta y setenta. Aplicando el coeficiente 4,5 nos lleva a una población aproximada en el ecuador del siglo XV en torno a los 300 habitantes $^{49}$.

- Gracias a la existencia de este lugar se han evitado homicidios, crímenes de collera, robos y otros delitos. Si el lugar de Monforte no estuviese po-

48. La legua tiene una equivalencia de $5.572 \mathrm{~m}$, con lo que la distancia resultante sería de 17 $\mathrm{Km}$ aproximadamente, lo que coincide con la distancia entre Elche y Monforte a través del camino real de Castilla. Información que agradecemos al profesor Salvador Palazón Ferrando.

49. Coeficiente utilizado por Agustín RuBio VeLA en «La población de Valencia en la Baja Edad Media», Hispania, 190 (1995), pp. 495-525. 
blado de cristianos estos actos los realizarían los almogávares granadinos sin ningún problema.

- Los habitantes de Monforte y sus predecesores son buenos peones y valientes hombres que conocen las rutas que utilizan los almogávares.

- La experiencia demuestra que cuando los almogávares granadinos y los renegados cristianos atacan en dicho territorio los vecinos de Monforte siguen a los atacantes, apresando a parte de los mismos.

- A pesar del temor que sienten los atacantes hacia los habitantes de Monforte no han cesado los homicidios, los asaltos, los robos.

- Hace pocos días dos ciudadanos de Orihuela, Nicolau de Molins y Marti Gronyo fueron matados violentamente y otras personas cautivadas y robadas cerca del lugar de Monforte. En un día pueden pasar los atacantes a territorio granadino.

- Si este lugar queda despoblado de cristianos los atacantes podrían actuar con impunidad, ya que cuando la noticia llegase a las otras villas o lugares de cristianos, habrían tenido tiempo de sobra para huir.

- El lugar de Monforte está a cuatro leguas de la villa de Alicante y forma parte de su contribución o término. Los vecinos de Alicante acuden a la partida de Monforte a recoger esparto y realizar otras actividades. Si el lugar se despuebla de cristianos y es ocupado por musulmanes dejarían de acudir los cristianos de Alicante al lugar de Monforte.

- Los mudéjares del valle de Elda se afanan de forma sutil en despoblar el lugar de Monforte de cristianos para repoblarlo con musulmanes.

- Esta situación además de reportar un "dan universal de tot lo regne" perjudica a la villa de Alicante. Los habitantes del lugar de Monforte han protestado a las autoridades de Alicante.

- El síndico de Alicante comunica al rey que ya se han poblado doce o quince casas de "moros". Estos mudéjares compran casas y tierras sin reparar en gastos para atraer a otros correligionarios y despoblar el lugar de cristianos.

- Estos mudéjares que han poblado Monforte cuando se produce un ataque de almogávares, no quieren salir a perseguirlos, ya que no les hacen daño en sus casas.

- Hace pocos días siete de los moros que estaban en Monforte se llevaron una joven cristiana a tierra de "moros" donde ha renegado, causando una gran ofensa y consternación entre los cristianos del territorio, preocupados por el mal ejemplo de esta acción frente a los moros.

- De las quince casas de pobladores mudéjares de Monforte no se recibe al año más que cincuenta sueldos, por lo que el beneficio que se obtiene de ellos es mínimo. 
- Por otra parte, a los mudéjares que quieran acudir a poblar Monforte se les puede preparar un lugar en Alicante y Orihuela. Si se instalan en Alicante y Orihuela no podrán actuar como en Monforte.

- Suplican al rey que ordene bajo fuertes penas que en breve tiempo fijado por las autoridades de Alicante y Orihuela, los musulmanes del lugar de Monforte abandonen con sus mujeres, hijos y familia dicho lugar, para que sea despoblado de mudéjares.

Juan II además de informar al baile general de la propuesta que había recibido de los mensajeros de Alicante y Orihuela, le ordenaba que recabase información de todo lo relatado y estudiase la solución más útil al bien público. El rey le muestra dos alternativas:

1. Que los "moros" que hay en la actualidad en el lugar de Monforte sigan ocupando sus casas, pero que no acudan más a poblar dicho lugar.

2. Que los mudéjares abandonen Monforte y se instalen en Alicante u Orihuela.

No tenemos más noticias sobre la evolución de la morería de Monforte, pero a la vista de la solución dictada por el rey es plausible pensar que las protestas elevadas por las autoridades de Alicante y Orihuela pudieron cercenar de golpe las posibilidades del poblamiento mudéjar del lugar.

\section{CONCLUSIÓN}

La situación fronteriza de la gobernación de Orihuela en el siglo XV con Castilla y con el reino de Granada y la facilidad de acceso a las morerías del interior, situadas en el curso del Vinalopó, facilitaban las acciones de los almogávares granadinos. La complicidad de sus correligionarios en el territorio de la gobernación creaba desconfianzas, sospechas y generaba tensiones entre los habitantes y las autoridades de las villas de Alicante y Orihuela hacia las morerías por la aparente impunidad con que podían actuar algunos musulmanes robando, matando y apresando cristianos. La reacción fue la de intentar reprimir estas acciones mediante represalias armadas y por la vía jurisdiccional, además de intentar crear morerías en territorio con predominio de población cristiana y frenar las expectativas de crecimiento de la población musulmana en localidades con población mayoritaria musulmana. Frente a estos intentos de sometimiento y control, la comunidad musulmana, que ofrecía una tenaz resistencia, respondía presionando a las autoridades cristianas de las morerías para frenar las competencias jurisdiccionales del gobernador, bajo amenazas de abandono y despoblamiento de la morería, a la vez que los señores, que no querían perder a sus vasallos mudéjares, hacían valer su jurisdicción empleando la fuerza de las armas si era necesario.

Los musulmanes que vivían en grandes morerías como las del valle de Elda se resistían a la asimilación cristiana utilizando diferentes estrategias. 
Una de ellas fue la colonización del cercano lugar de Monforte. Otra, a falta de nuevos estudios, es una apuesta como comunidad por el crecimiento económico y el máximo aprovechamiento de los recursos naturales del medio circundante, lo que posiblemente terminó, junto a los factores de asimilación. cultural y religiosa, por enfrentarles con las comunidades cristianas vecinas. En todo caso y utilizando la propuesta que hizo Dolors Bramón en 1987 en Teruel, creo que en las tres grandes morerías de la gobernación, la musulmana era una comunidad "que era y quiso ser musulmana y fue, precisamente, discriminada por ello" ${ }^{\prime 50}$ y comparto totalmente su idea de que el mudéjar del ámbito rural no era un "labrador sumiso" ni un "servil esquirol"51. Creo que las páginas anteriores demuestran, en todo caso, lo contrario.

\section{RESUMEN}

Durante el siglo XV la gobernación de Orihuela fue el escenario de una difícil convivencia entre cristianos y musulmanes en un territorio fronterizo. Utilizando las fuentes conservadas para este período escuchamos la voz de los vencedores, en la lucha por la hegemonía espacial que enfrentó durante siglos en la Península Ibérica a cristianos y musulmanes. En este artículo y a través de estos testimonios analizamos la actitud de los cristianos ante la presencia de morerías muy pobladas en territorios colindantes y las tensiones que se produjeron entre ambas comunidades. Finalmente estudiamos la contradictoria posición de los cristianos ante dos intentos de establecer morerías reales en Orihuela y Monforte, situadas ambas en territorio de la gobernación de Orihuela.

\section{ABSTRACT}

In the Fifteenth Century the government of Orihuela, frontier territory, was the scene of a hard life for Cristians and Moslems living together. Using the available sources for this period we hear the voice of the winners in their fight for the hegemony of the land, struggle that confronted Christians and Moslems for centuries. In this article and through these testimonies, we analize the actitude of the Christians with the presence of very populated morish quarters in adjacent territories, and the tensions created between both comunities. We finally study the contradictory position of the Christians at the time the Moslems tried to establish royal moorish quarters in Orihuela and Monforte, both of them placed in territory under Orihuela government.

50. D. BRAMÓN, «Estado de la cuestión...», p. 237.

51. Ibídem. 